\title{
Histiocitosis, una visión práctica para el dermatólogo
}

\author{
Histocytosis, a practical view for the dermatologist

\section{Lina Vanessa Gómez ${ }^{1}$, Rodrigo Restrepo², Natalia Buchely ${ }^{3}$} \\ 1. Médica, residente de III año de Dermatología, Universidad Pontificia Bolivariana, Medellín, Colombia. \\ 2. Médico dermatopatólogo; jefe, Programa de Especialización en Dermatopatología, Universidad CES, Medellín, Colombia; profesor \\ de Dermatopatología, Universidad Pontificia Bolivariana, Medellín, Colombia. \\ 3. Médica patóloga, Universidad Militar, fellow en Dermatopatología, Universidad CES, Medellín, Colombia.
}

\section{RESUMEN}

Las histiocitosis comprenden un grupo amplio de alteraciones caracterizadas por proliferación clonal anormal de histiocitos en los diferentes tejidos. Las manifestaciones clínicas pueden estar limitadas a la piel, incluso, pueden ser el primer signo de la enfermedad o pueden acompañarse de compromiso sistémico, como ocurre en la mayoría de los casos. La clasificación ha sido compleja y controversial a lo largo de la historia. La forma más sencilla de abordarlas las divide en histiocitosis de células de Langerhans y no Langerhans e histocitosis malignas.

Se presenta una revisión de tema de las histiocitosis benignas desde un enfoque inmunohistoquímico útil y con los aspectos clínicos más relevantes para la práctica dermatológica.

PALABRAS CLAVE: histiocitos, histiocitosis de células de Langerhans, histiocitosis de células no Langerhans.

\section{SUMMARY}

Histiocytosis comprises a broad group of disorders characterized by abnormal clonal proliferation of histiocytes in different tissues. Clinical manifestations may be limited to the skin and can even be the first sign of the disease, or they may be accompanied by systemic involvement as in most cases. Classification has been complex and controversial through history, the simplest way to approach divides these in Langerhans cell and non-Langerhans cell histiocytosis and malignant histiocytosis.

A review of benign histiocytic disorders from the immunohistochemical approach with the most relevant clinical aspects useful for dermatological practice is presented.

KEY WORDS: Histiocytes, Langerhans cell histiocytosis, non-Langerhans cell histiocytosis.

\section{INTRODUCCIÓN}

Las histiocitosis comprenden un grupo de enfermedades que tienen en común la proliferación de células del sistema fagocítico mononuclear, implicadas en reac-

\section{Correspondencia:}

Lina Vanessa Gómez

Email:

lahegos@hotmail.com

Recibido: 7 de enero de 2016

Aceptado: 15 de julio de 2016

No se reportan conflictos de interés. 


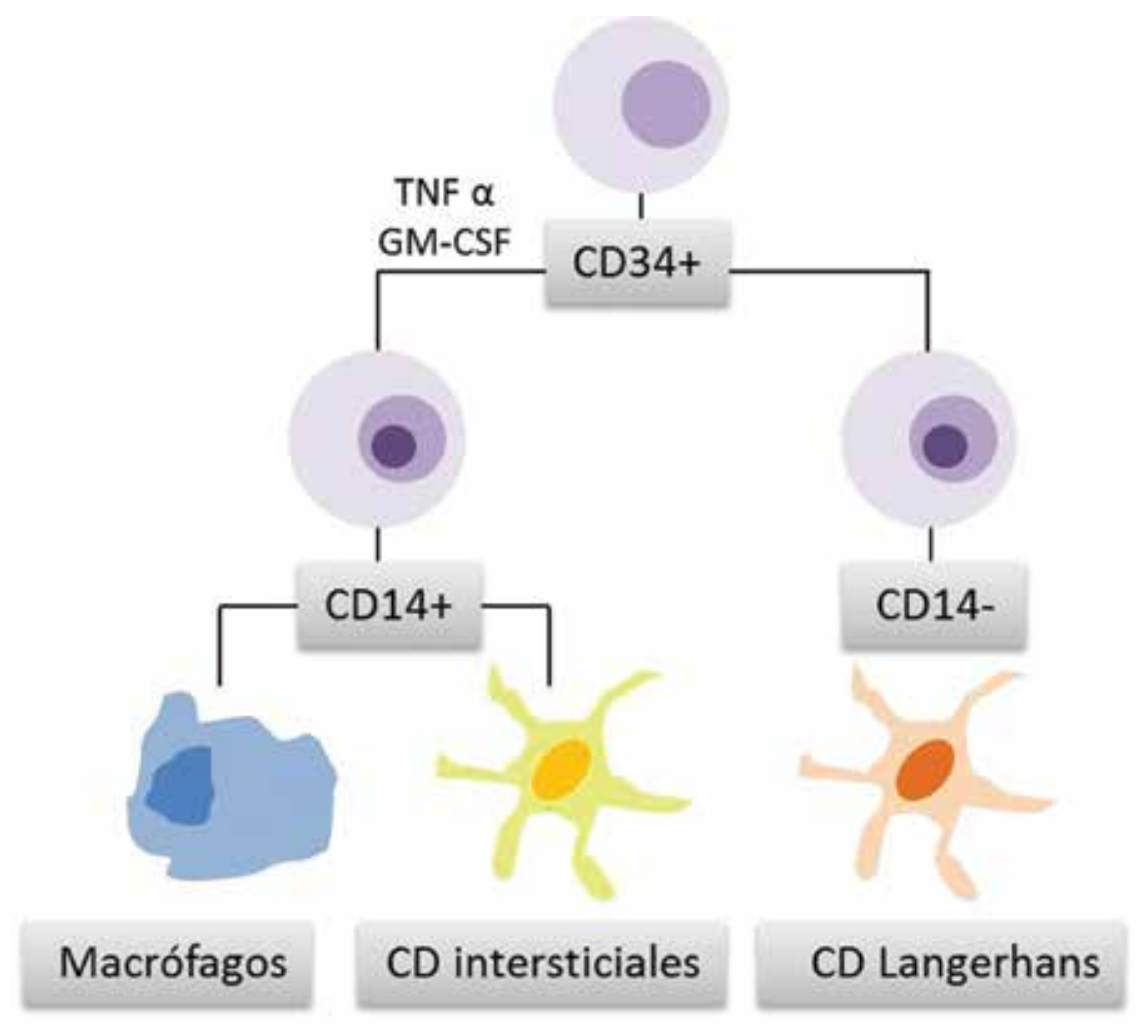

FIGURA 1. Ontogénesis de los histiocitos: diagrama esquemático del origen de los histiocitos, derivados de una célula madre hematopoyética común $\mathrm{CD}_{34}+$ en médula ósea. En presencia del factor de necrosis tumoral alfa (TNF $\alpha$ ) y del factor estimulante de colonias de granulocitos macrófagos (GM-CSF), inducen la formación de dos líneas celulares principales: CD14+, que dará origen a las células dendríticas dérmicas o intersticiales y a los monocitos macrófagos, y CD14-, que dará origen a las células de Langerhans.

ciones inflamatorias inmunitarias y no inmunitarias. Se derivan de una célula progenitora común $\mathrm{CD}_{34+}$ en la médula ósea ${ }^{1,2}$ (FIGURA 1).

Desde el punto de vista funcional, existen tres tipos de histiocitos cutáneos: 1) las células de Langerhans que migran desde la epidermis y hacia ella, y funcionan como células presentadoras de antígeno; 2) las células dendríticas dérmicas de localización perivascular, las cuales pueden ser de tipo 1, dendrocitos dérmicos (intersticiales) que residen en la dermis papilar y tienen funciones de fagocitosis, presentación antigénica, reparación de tejidos e inflamación, o de tipo 2, dendrocitos foliculares de un origen no hematopoyético, que residen en la dermis reticular y cuya función es más incierta, y 3) las células macrófagos mononucleares que migran desde la dermis y hacia ella y tienen propiedades fagocíticas y de presentación antigénica ${ }^{3}$.

\section{CLASIFICACIÓN}

La disfunción de estos tipos de histiocitos comprende un grupo conocido pero pobremente entendido de alteraciones cutáneas y sistémicas ${ }^{4}$.

La Histiocyte Society propuso, en 1987, la clasificación de estas enfermedades en tres clases ${ }^{5}$ :

- Histiocitosis de células de Langerhans.

- Histiocitosis del sistema fagocítico mononuclear.

- Histiocitosis malignas.

En 1997, la misma sociedad propuso reclasificar las histiocitosis, según su comportamiento, en enfermedades de comportamiento biológico variable relacionadas con células dendríticas o macrófagos, y en enfermedades malignas relacionadas con células dendríticas o monocitos macrófagos ${ }^{6}$. 


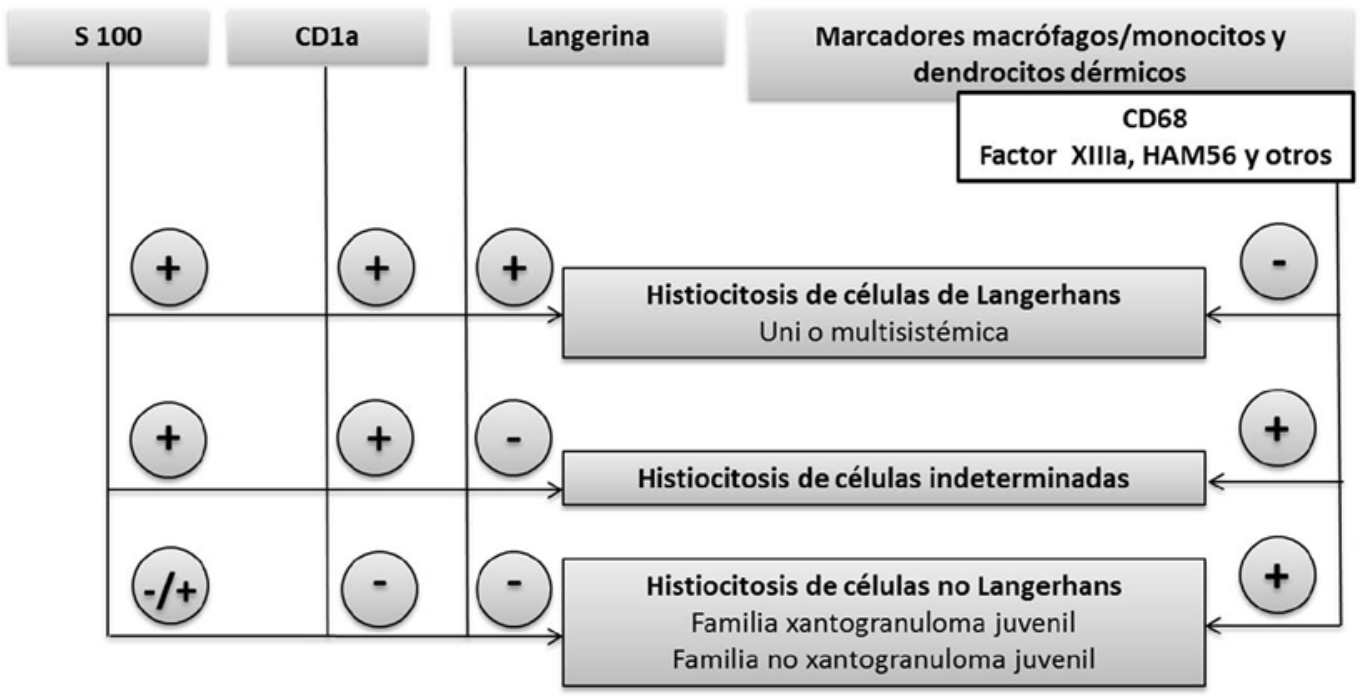

FIGURA 2. Clasificación inmunohistoquímica de las histiocitosis: algoritmo ilustrativo de los principales marcadores antigénicos de los histiocitos Langerhans y no Langerhans, y cómo se correlacionan con el tipo de histiocitosis. Estos resultados son una guía y pueden variar en casos específicos.

En esta revisión, se abordan las histiocitosis de tipo I y II con base en la clasificación de 1987, pues continúa siendo la más útil y sencilla en la práctica clínica.

\section{VISIÓN INMUNOHISTOQUÍMICA DE LAS HISTIOCITOSIS}

Con el advenimiento de la inmunohistoquímica y de la microscopía electrónica, el panorama para entender las histiocitosis se ha aclarado un poco más. La utilización de marcadores celulares clásicos permite agrupar las histiocitosis en las de células de Langerhans y las de células no Langerhans, aunque se sabe que puede existir superposición a la hora de evaluar la positividad de estos marcadores, entre los diferentes subtipos ${ }^{3,7}$ (FIGURA 2).

\section{HISTIOCITOSIS DE CÉLULAS DE LANGERHANS}

Este grupo de histiocitosis se caracterizan por una alteración clonal proliferativa de células de Langerhans (FIGURA 3, A Y B) que expresan, típicamente, un in- munofenotipo positivo para S100, CD1a y langerhina (CD207) (FIGURA 3, C Y D), y en las que, por medio de microscopía electrónica, pueden identificarse los gránulos citoplásmicos de Birbeck (FIGURA 3, F) ${ }^{3,8}$.

\section{Epidemiología}

Las histiocitosis de células de Langerhans tienen distribución mundial. Los estudios epidemiológicos son escasos debidos a la rareza de la enfermedad, se ha reportado una incidencia variable de 1,5 casos por millón en adultos hasta 5 casos por millón en niños ${ }^{9-11}$. Puede presentarse desde el periodo neonatal hasta la edad adulta; su pico de incidencia ocurre entre los uno y los tres años de vida y es más frecuente en hombres que en mujeres con una relación de 2:1,2. Pese a que se describen algunos casos familiares, particularmente en gemelos, hay poca evidencia que sustente un componente genético ${ }^{12}$.

Existen, también, algunos casos asociados a neoplasias malignas en los que se reporta un aumento de la incidencia de tumores sólidos como osteosarcomas y neoplasias malignas hematológicas, principalmente leucemias mielomonocíticas ${ }^{13}$. Se han descrito dos patrones: en el primero, la neoplasia maligna se de- 


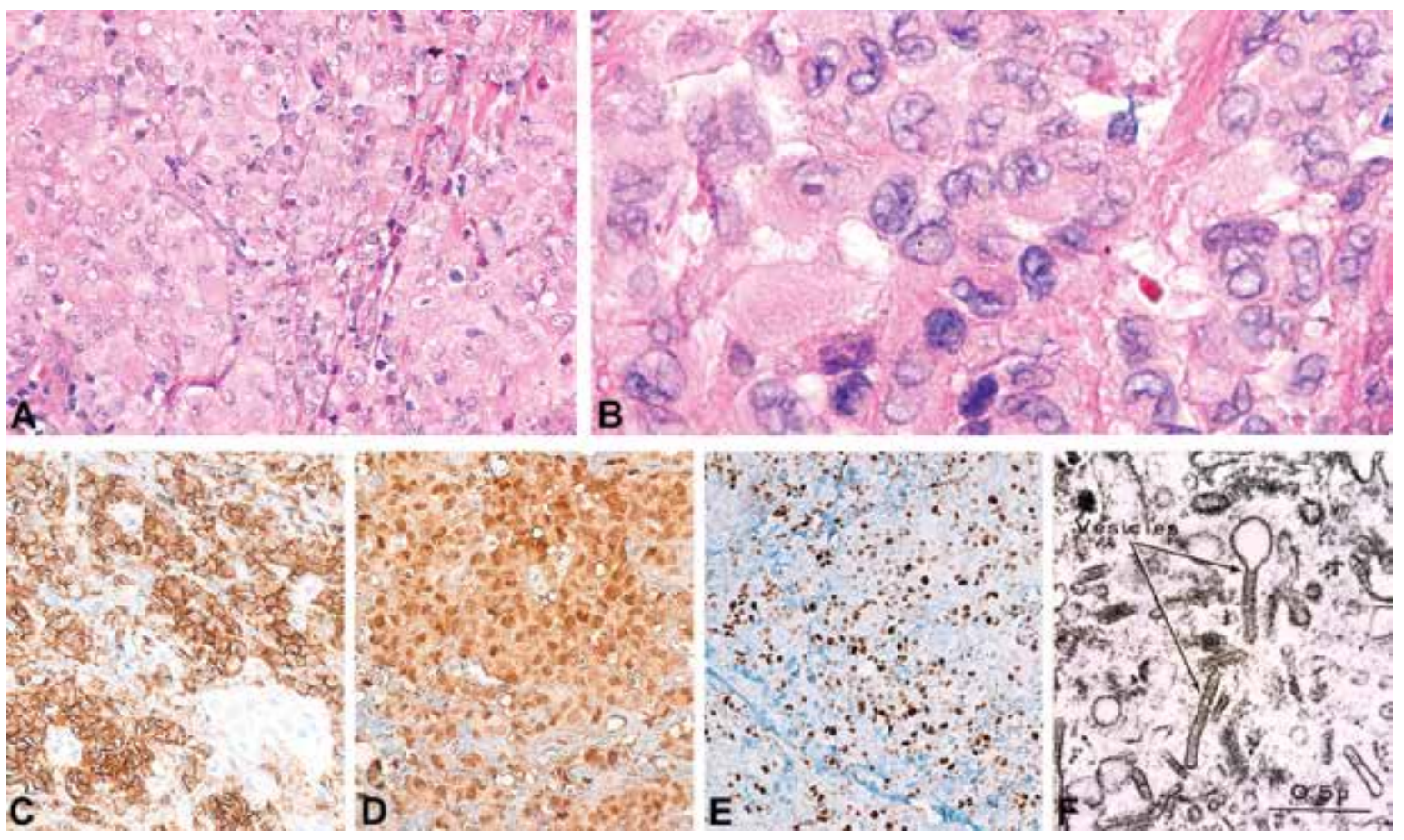

FIGURA 3. Histología de la histiocitosis de células de Langerhans. A y B. Células de Langerhans. Nótese el citoplasma amplio eosinófilo y el núcleo con forma de riñón. Hay algunos eosinófilos y linfocitos dispersos. Hematoxilina y eosina, A: 40X y B: 10oX. C. Inmunohistoquímica: positiva para CD1a, 40X. D. Inmunohistoquímica: positiva para S100, 40X. E. Inmunohistoquímica: positiva para Ki67, 40X. F. Micrografía electrónica: múltiples gránulos de Birbeck, uno de las cuales muestra una barra con una densidad lineal central y estrías cruzadas, con una expansión bulbosa clara (vesículas) en un extremo. Su apariencia se asemeja a la de una raqueta de tenis. Fuente: Creative commons. Langerhans cell histiocytosis - Birbeck granules. https:// commons.wikimedia.org/wiki/File:Langerhans_cell_histiocytosis___Birbeck_granules.jpg.

sarrolla después de la quimioterapia contra la histiocitosis de células de Langerhans, lo cual sugiere que sería inducida por dicho tratamiento; en el segundo, cuando hay antecedentes de leucemia o de tumores sólidos, existe un aumento de la posibilidad de desarrollar histiocitosis de células de Langerhans, por predisposición genética ${ }^{14}$.

En Colombia, en un estudio retrospectivo del Instituto Nacional de Cancerología, que comprendió un periodo de 10 años, se describieron 34 pacientes con histiocitosis de células de Langerhans; se encontró que la edad media para el diagnóstico eran los tres años de vida, con predominio en el sexo masculino, y hubo compromiso de la piel en $41 \%$ de los $\operatorname{casos}^{15}$.

\section{Patogénesis}

La patogénesis de estas alteraciones se desconoce ${ }^{1,3,16}$. Se han implicado factores genéticos con reportes en gemelos, principalmente homocigóticos, pero, en general, los casos familiares son raros, lo cual no favorece una influencia hereditaria ${ }^{12}$. Entre los agentes infecciosos se mencionan especialmente algunos virus (virus herpes 6, citomegalovirus, adenovirus, parvovirus) como activadores de histiocitos por mecanismos inmunológicos ${ }^{1,3}$; sin embargo, no se ha logrado demostrar su presencia en los tejidos afectados mediante reacción en cadena de la polimerasa (PCR) u otras técnicas moleculares ${ }^{17}$. Finalmente, se ha propuesto que las disfunciones del sistema inmunológico (anormalidades de linfocitos, aumento de citocinas como IL1, IL2, IL4, IL10 e IFNa, y moléculas de adhesión celular) y las alteraciones en la división celular (los histiocitos se frenan en un estado de inmadurez y de activación parcial), alteran la función de presentación antigénica de los histiocitos, lo que lleva a una interacción aberrante con los linfocitos $\mathrm{T}^{3,16,18}$.

También existe controversia acerca de la naturaleza reactiva o neoplásica de la histiocitosis de células de Langerhans ${ }^{16,19}$. Los factores a favor de un proceso reactivo son: son células muy diferenciadas; en la his- 
ENFERMEDAD UNISISTÉMICA

\begin{tabular}{ll}
\hline Sitio único (localizada) & ENFERMEDAD UNISISTÉMICA \\
& $\begin{array}{l}\text { Óseo monostótico } \\
\text { Aislado en piel } \\
\text { Ganglio solitario } \\
\text { Sitios múltiples }\end{array}$ \\
& $\begin{array}{l}\text { Óseo poliostótico } \\
\text { Enfermedad ósea multifocal (dos o más huesos) } \\
\text { Múltiples ganglios }\end{array}$ \\
\hline Grupo de bajo riesgo & ENFEMEDAD MULTISISTÉMICA \\
\hline Grupo de alto riesgo & $\begin{array}{l}\text { Enfermedad diseminada, compromiso de dos o más órganos: piel, } \\
\text { hueso, ganglio, hipófisis }\end{array}$ \\
\hline
\end{tabular}

TABLA 1. Clasificación de la histiocitosis de células de Langerhans según su extensión.

tología, las lesiones tienen aspecto granulomatoso, con escasas mitosis; y, hay casos de regresión espontánea. Los factores a favor de un proceso neoplásico, son: las células de Langerhans se derivan de la médula ósea y muestran expansión clonal; existen casos familiares ( $1 \%)$; hay hallazgos de inestabilidad cromosómica y acortamiento de telómeros; existe aumento de la expresión de proteínas Ki67, p53, H-ras, c-myc, que corresponden a vías inhibitorias y estimuladoras de proliferación y apoptosis celular; y finalmente se ha demostrado concomitancia de esta histiocitosis con síndromes mielodisplásicos ${ }^{16,18,19}$.

En 2010, Badalian-Very G, et al., en un estudio que buscaba identificar nuevas vías patogénicas de estas histiocitosis, reportaron mutaciones en la vía de transducción del receptor de la tirosin-cinasa RTK/RASBRAF, en el $57 \%$ de los especímenes con histiocitosis de células de Langerhans examinados, pero su expresión no se correlacionó con la gravedad de la enfermedad ${ }^{20}$. Posteriormente, en estudios más recientes se ha reportado prevalencia de la mutación BRAF en 38 a $69 \%$ de los casos; esta mutación es oncogénicamente activa, llevando a la activación continua de la vía de las cinasas MAP (Mitogen-Activated Protein), lo cual sugiere más que se trata de una enfermedad de naturaleza neoplásica que tiene comportamiento biológico variable ${ }^{21}$.

\section{Manifestaciones clínicas}

Constituyen un grupo de enfermedades con un espectro amplio de manifestaciones; pueden ser asintomáticas con curso clínico lento, hasta sistémicas y agresivas con compromiso de múltiples órganos ${ }^{1-3}$.

Históricamente, las histiocitosis de células de Lan- gerhans se distinguieron con diversos nombres, como: enfermedad de Letterer-Siwe, enfermedad de Hand-Schüller-Christian, granuloma eosinófilo y enfermedad de Hashimoto-Pritzker ${ }^{3,5,18}$. En 1997, con la reclasificación de la Histiocyte Society ${ }^{6}$, se recomendó no usar más estos nombres y clasificar la enfermedad, según su extensión, en unisistémica o multisistémica. La unisistémica puede localizarse en uno o en múltiples sitios y, generalmente, tiene un curso clínico asintomático o con síntomas leves. La multisistémica (dos o más órganos) puede ser de bajo riesgo (80 \% de los casos) o de alto riesgo (20 \% de los casos), según el tipo de órgano comprometido, con un curso clínico más grave $e^{4,16,19}$. En la TABLA 1 se ilustra la clasificación actual de este tipo de histiocitosis.

COMPROMISO CUTÁNEO: Las manifestaciones cutáneas son muy comunes y pueden estar presentes en 40 a $50 \%$ de los $\operatorname{casos}^{18}$, incluso, como manifestación inicial de la enfermedad ${ }^{1}$. La piel puede ser el único sitio comprometido; sin embargo, la enfermedad puede progresar y comprometer otros órganos ${ }^{1,2}$.

Las lesiones pueden ser muy variables, como: pápulas descamativas eritematosas o de color café, erosiones, úlceras, petequias, vesículas, pústulas, nódulos y placas ${ }^{18,22}$.

El cuero cabelludo es el sitio más afectado; el compromiso suele ser difuso, con parches eritematosos descamativos y escamas oleosas, muy similar al de una dermatitis seborreica ${ }^{1}$. Además, pueden verse petequias y pequeñas erosiones con costras y, en casos graves, alopecia 22-24 (FIGURA 4).

Los pliegues de la piel son el segundo sitio en frecuencia $^{18}$, comprenden el área inguinal, la perianal, 


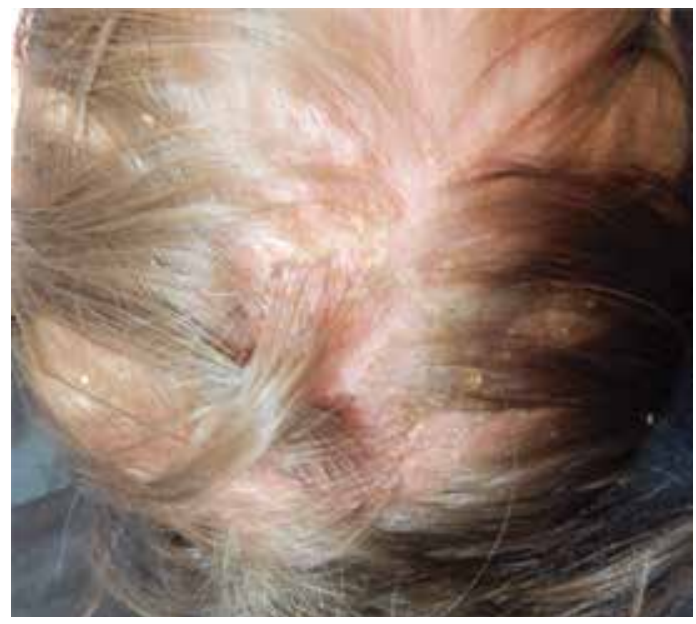

FiguRA 4. Cuero cabelludo: descamación amarilla oleosa sobre una placa eritematosa en la región interparietal.

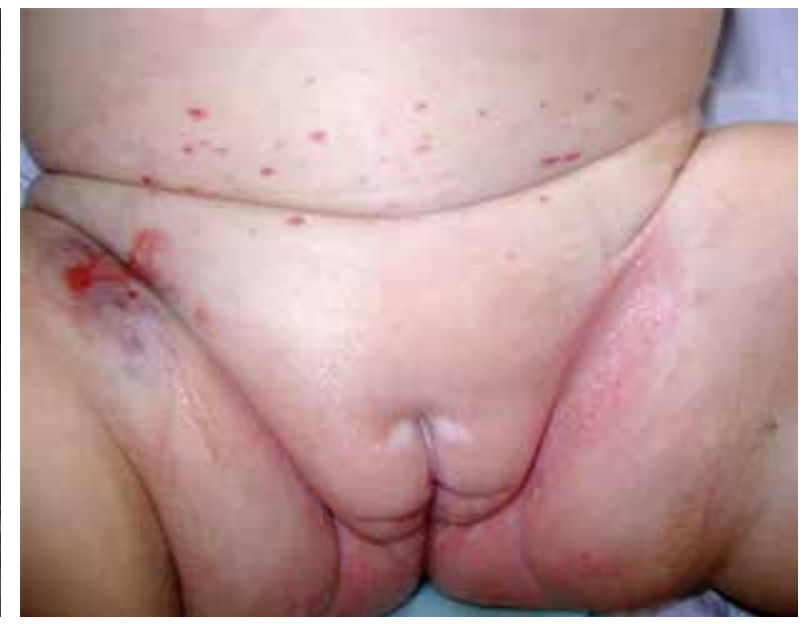

FIGURA 5. Compromiso de pliegues inguinales con un área de ulceración y petequias. la inframamaria, el cuello y las axilas. Inicialmente, la erupción es máculo-papular eritematosa, pero pueden aparecer rápidamente erosiones y úlceras ${ }^{22,23}$ (FIGURA 5).

En el tronco, las lesiones se localizan en la parte media de la espalda, respetando los hombros ${ }^{22,24}$. En niños, y particularmente en pacientes trombocitopénicos, esta erupción puede ser purpúrica, lo que se considera un signo de mal pronóstico ${ }^{1}$.

Otros lugares de afectación incluyen la cara en la región paranasal y la preauricular, y las mucosas, principalmente la periodontal, con infiltración de las encías $^{25}$; el compromiso ungular que es más frecuente en niños, quienes desarrollan onicorrexis, hiperqueratosis subungular, paroniquia, onicólisis y distrofia ${ }^{26,27}$.

COMPROMISO SISTÉMICO: Es muy variable, se ha reportado compromiso óseo, hepático, esplénico, pulmonar, ganglionar, endocrino, gastrointestinal, de médula ósea y del sistema nervioso central ${ }^{4,22,28}$. Los principales hallazgos en los diferentes órganos, se resumen en la TABLA 2.

\section{Diagnóstico}

Dado el amplio y variable espectro clínico de las histiocitosis de células de Langerhans, se requiere confirmación histopatológica ${ }^{18}$. En 1989, la Histiocyte Society propuso unos criterios diagnósticos que incluían la morfología clásica al microscopio de luz, confirmada por la presencia de gránulos de Birbeck en la micros- copía electrónica, por la demostración del CD1a en la inmunohistoquímica o por ambas (FIGURA 3, C Y F) ${ }^{29}$. En la actualidad, la presencia de gránulos de Birbeck puede ser comprobada por la tinción inmunohistoquímica de la proteína langerina (CD207), un tipo de lectina $\mathrm{C}$, específica de la membrana y del citoplasma de las células de Langerhans, que induce la formación de estos gránulos ${ }^{30}$. La positividad de CD1a, de la langerina o de ambas en la lesión es la prueba estándar actual para el diagnóstico de estas histiocitosis ${ }^{16}$.

Así como existe variabilidad en la presentación clínica, puede haberla también en los hallazgos histopatológicos ${ }^{3}$. En general, se observan células histiocíticas de apariencia ovalada, con citoplasma claro moderadamente eosinofílico, núcleo reniforme o con aspecto de grano de café y nucléolo discreto (FIGURA 3, A Y B), correspondientes a células de Langerhans que infiltran la dermis y, en ocasiones, con el fenómeno de epidermotropismo ${ }^{8,31}$. En las lesiones tempranas, el infiltrado puede acompañarse de eosinófilos (FIGURA 3, A), neutrófilos, linfocitos y células plasmáticas; y las lesiones tardías, pueden tomar el aspecto de lesiones xantomatosas, granulomatosas y con fibrosis. La presencia de mitosis es variable, en general escasa, pero, ocasionalmente se puede documentar una actividad proliferativa relativamente alta (FIGURA 3, E). Las características secundarias incluyen formación de costras, pústulas, hemorragias y necrosis ${ }^{3,8}$.

Una vez establecido el diagnóstico, se deben practicar exámenes paraclínicos para determinar si existe dis- 


\begin{tabular}{|c|c|}
\hline ÓRGANO & COMPROMISO \\
\hline Hueso & $\begin{array}{l}\text { Principal sitio de compromiso sistémico (80 \%) } \\
\text { Más frecuente en niños y adultos jóvenes } \\
\text { Lesiones osteolíticas. Apariencia en sacabocado a los rayos x } \\
\text { Asintomáticas, edema, dolor o fracturas } \\
\text { Localización: cráneoshuesos largos`huesos planos }\end{array}$ \\
\hline Hígado y bazo & $\begin{array}{l}\text { Segundo sitio de compromiso sistémico (15-50\%) } \\
\text { Hepatoesplenomegalia, colestasis }\end{array}$ \\
\hline Pulmón & $\begin{array}{l}\text { Más frecuente en adultos fumadores } \\
\text { Tos, dolor torácico, disnea. Patrón reticulonodular a los rayos } X\end{array}$ \\
\hline Ganglios & $\begin{array}{l}\text { Compromiso inicial en el } 10 \% \text { de los niños } \\
\text { Localización: principalmente en ganglios cervicales }\end{array}$ \\
\hline Endocrino & $\begin{array}{l}\text { Principal manifestación: diabetes insípida, más en pacientes con compromiso } \\
\text { craneofacial } \\
\text { Otros sitios afectados: tiroides, timo, páncreas, gónadas }\end{array}$ \\
\hline Gastrointestinal & $\begin{array}{l}\text { Forma inusual de compromiso en niños } \\
\text { Enteropatía perdedora de proteínas y pérdida de peso }\end{array}$ \\
\hline Médula ósea & $\begin{array}{l}\text { Raro, más en el curso tardío de la enfermedad } \\
\text { Anemia, leucopenia, trombocitopenia o pancitopenia }\end{array}$ \\
\hline Sistema nervioso central & $\begin{array}{l}\text { Raro } \\
\text { Tumores de hipófisis y lesiones degenerativas }\end{array}$ \\
\hline
\end{tabular}

TABLA 2. Principales hallazgos sistémicos según el órgano afectado.

\begin{tabular}{l} 
ESTUDIOS INICIALES \\
PARA EVALUAR EL COMPROMISO SISTÉMICO \\
Hemoleucograma y velocidad de sedimentación \\
globular \\
Proteínas totales, albúmina \\
Pruebas de función hepática, tiempos de \\
coagulación \\
Pruebas de función renal, uroanálisis \\
Electrolitos, glucemia \\
Radiografía de tórax y huesos \\
Ecografía abdominal \\
\hline
\end{tabular}

TABLA 3. Exámenes paraclínicos iniciales para evaluar un posible compromiso sistémico.

función orgánica, en busca de citopenias, desnutrición, disfunción hepática, diabetes insípida, compromiso pulmonar y visceromegalias, entre otros ${ }^{18}$ (TABLA 3). Según la presencia de anormalidades en los anteriores, se solicitan estudios más especializados, como biopsia dirigida y aspiración de médula ósea, tomografía computadorizada (TC) pulmonar de alta resolución, biopsia hepática y resonancia magnética cerebral ${ }^{28}$.

\section{Diagnóstico diferencial}

Por la variedad morfológica de las lesiones, se incluyen muchos diagnósticos diferenciales; es útil agruparlos según el sitio de presentación ${ }^{1}$ : la afección del cuero cabelludo incluye dermatitis seborreica, tiña capitis y foliculitis decalvans; el compromiso de los pliegues cutáneos incluye dermatitis del pañal, intertrigo candidiásico, enfermedad de Darier e hidradenitis supurativa; $y$, finalmente, las lesiones en el tronco incluyen histiocitosis de células no Langerhans, urticaria pigmentosa, liquen nitidus, miliaria y escabiosis ${ }^{24}$.

\section{Tratamiento}

El tratamiento depende de la extensión de la enfermedad, de la edad del paciente y de la localización de las lesiones ${ }^{1}$. Existen diferentes guías de manejo y estudios previos o en curso, recomendados por la Histiocyte Society y disponibles en su página web (http:// www.histiocytesociety.org).

Antes de iniciar el tratamiento, lo más importante es determinar o clasificar el tipo de compromiso (uno o varios sistemas) y el riesgo (bajo o alto), como se expuso anteriormente ${ }^{16,18}$. 
ENFERMEDAD UNISISTÉMICA. Después de practicar los estudios pertinentes, los pacientes con este tipo de afectación pueden ser remitidos a la especialidad médica indicada, dependiendo del órgano afectado ${ }^{28}$.

En lo que respecta al compromiso cutáneo, en algunos casos aconseja la conducta de observación dada la posibilidad de remisión espontánea ${ }^{18}$, incluso, para algunos autores esta sería la mejor opción pues se describe que más del $50 \%$ remiten en unos pocos meses ${ }^{16}$. Entre los tratamientos disponibles, se reportan: corticoesteroides tópicos, cuya eficacia es limitada, pues la mayoría de las lesiones se diagnostican cuando no hay mejoría con ellos $^{28}$, tacrolimus tópico ${ }^{16}$, imiquimod tópico ${ }^{1}$, mostaza nitrogenada tópica ${ }^{32}$, fototerapia PUVA para adultos ${ }^{33} \mathrm{O}$ $\mathrm{UVB}^{34}$ y láser de $\mathrm{CO}_{2}$ para el granuloma eosinófilo periorificial como medida ablativa ${ }^{1}$. En casos resistentes o con compromiso extenso, se describe el uso de esteroides sistémicos, como prednisolona a dosis de $1 \mathrm{mg} / \mathrm{kg}^{16,28}$; la talidomida es otra alternativa que ha mostrado ser efectiva para inducir remisión de las lesiones cutáneas, a dosis de $100 \mathrm{mg} /$ día durante un mes, seguida de $50 \mathrm{mg} /$ día durante dos meses ${ }^{35}$; también, la isotretinoína oral, a dosis diarias de $1,5 \mathrm{mg} / \mathrm{kg}^{36} \mathrm{y}$, con menor evidencia clínica, el metotrexato ${ }^{37} \mathrm{y}$ la azatioprina ${ }^{38}$.

En la serie de casos del Instituto Nacional de Cancerología, aquellos con enfermedad localizada o limitada a la piel fueron tratados con esteroides tópicos o sistémicos, radioterapia y criocirugía ${ }^{15}$.

El vemurafenib, como inhibidor de la cinasa BRAF, aparece en un reporte en la literatura, en una mujer con histiocitosis de células de Langerhans y lesiones generalizadas, pero sin compromiso visceral, que no había mejorado con esteroides y talidomida, a quien se le administraron dosis de $960 \mathrm{mg}$ dos veces al día, y presentó mejoría clínica e histológica tras tres semanas de tratamiento ${ }^{39}$.

Finalmente, la escisión quirúrgica solo se considera en casos de nódulos solitarios, pero nunca se justifica el uso de cirugías extensas ${ }^{16,28}$.

ENFERMEDAD MULTISISTÉMICA. Al paciente con esta afectación, se le debe ofrecer tratamiento sistémico; sin embargo, no existe consenso sobre cuál es el más efectivo y seguro; el objetivo primario es reducir la mortalidad, y prevenir las reactivaciones y secuelas ${ }^{16}$. Se han descrito diferentes protocolos en ensayos clínicos realizados por la Histiocyte Society ${ }^{4,19,28}$; actualmente, se está llevando a cabo el cuarto ensayo clínico en 23 países. Se ha demostrado una mayor tasa de mejoría, menor reactivación y menor riesgo de desarrollar diabetes insípida, en pacientes tratados con poliquimioterapia; además, la falta de mejoría tras seis semanas de tratamiento indica un pronóstico desfavorable $^{28}$.

La primera línea de tratamiento consiste en vinblastina intravenosa $\left(6 \mathrm{mg} / \mathrm{m}^{2} /\right.$ semana $)$ junto con prednisolona oral $\left(40 \mathrm{mg} / \mathrm{m}^{2} /\right.$ día $)$ durante seis semanas, por uno o dos ciclos, según la reacción inicial, seguido de un año con terapia de mantenimiento, en el que se disminuye la frecuencia de los ciclos a cada tres semanas. Esto ha demostrado disminuir las recaídas $^{28}$. La segunda línea de tratamiento incluye cladribina, citarabina, metotrexato, ciclosporina, ciclofosfamida, doxorubicina, retinoides o interferón, y el trasplante de médula ósea ${ }^{19,28,38}$.

\section{Pronóstico}

El curso clínico de la enfermedad depende de la edad en que se inició, el número y tipo de órganos comprometidos, y si hay o no disfunción de estos, y de la rapidez de mejoría con el tratamiento ${ }^{28,38}$. En general, a una edad de inicio más temprana (menores de dos años) es peor el pronóstico, excepto en casos congénitos, la mayoría de los cuales remiten espontáneamente ${ }^{2}$.

La tasa de supervivencia con compromiso unisistémico o mutisistémico de bajo riesgo, es cercana al $100 \%$ a los cinco años, mientras que, si hay compromiso multisistémico de alto riesgo, se reduce a $84 \%$ a los cinco años ${ }^{40,41}$.

En la serie del Instituto Nacional de Cancerología, durante un periodo de seguimiento promedio de 3,48 años, el 20,5 \% de los pacientes murieron en un periodo menor de tres años; de ellos, el 71,4 \% tenían enfermedad multisistémica ${ }^{15}$.

A los pacientes con compromiso multisistémico debe hacérseles seguimiento cada seis meses, por lo menos, durante cinco años después del finalizado el tratamiento o cinco años después de la última reactivación de la enfermedad ${ }^{28}$. Se han descrito secuelas esqueléticas, dentales, endocrinas, auditivas y del sistema nervioso central ${ }^{4}$.

\section{HISTIOCITOSIS DE CÉLULAS NO LANGERHANS}

Las histiocitosis de células no Langerhans son un grupo muy heterogéneo de enfermedades caracterizadas por una alteración clonal proliferativa de células dendríticas dérmicas, en su mayoría monocitos y macrófagos $^{42}$, con apariencia espumosa típica (FIGURA 6, A Y B) y cuyo marcador inmunohistoquímico por 
excelencia es el CD68 ${ }^{8}$ (FIGURA 6, C Y D); otra característica importante es la negatividad de los marcadores para células de Langerhans, como el CD1a y la langerina (FIGURA 6, E).

En 2005, Weitzman, et al., dividieron las histiocitosis de células no Langerhans en dos familias, según la ontogénesis de las células: la familia xantogranuloma juvenil, derivada de los dendrocitos dérmicos, y la familia no xantogranuloma juvenil, derivada de

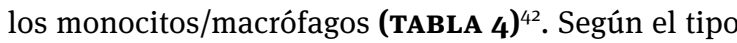
enfermedad, hay expresión variable de otros marcadores, como el factor XIIIa, la HAM56, la fascina y la
CD163, encontrándose incluso en algunos casos positividad para $\mathrm{S}_{100} 0^{3,8,42}$.

\section{Epidemiología}

Como en las de células de Langerhans, la mayoría de los casos de histiocitosis de células no Langerhans con enfermedad diseminada o sistémica ocurren en la infancia, principalmente en los primeros diez años de vida. Las lesiones solitarias pueden aparecer a cualquier edad ${ }^{43}$.

Visto de otra manera, se dice que las alteraciones de
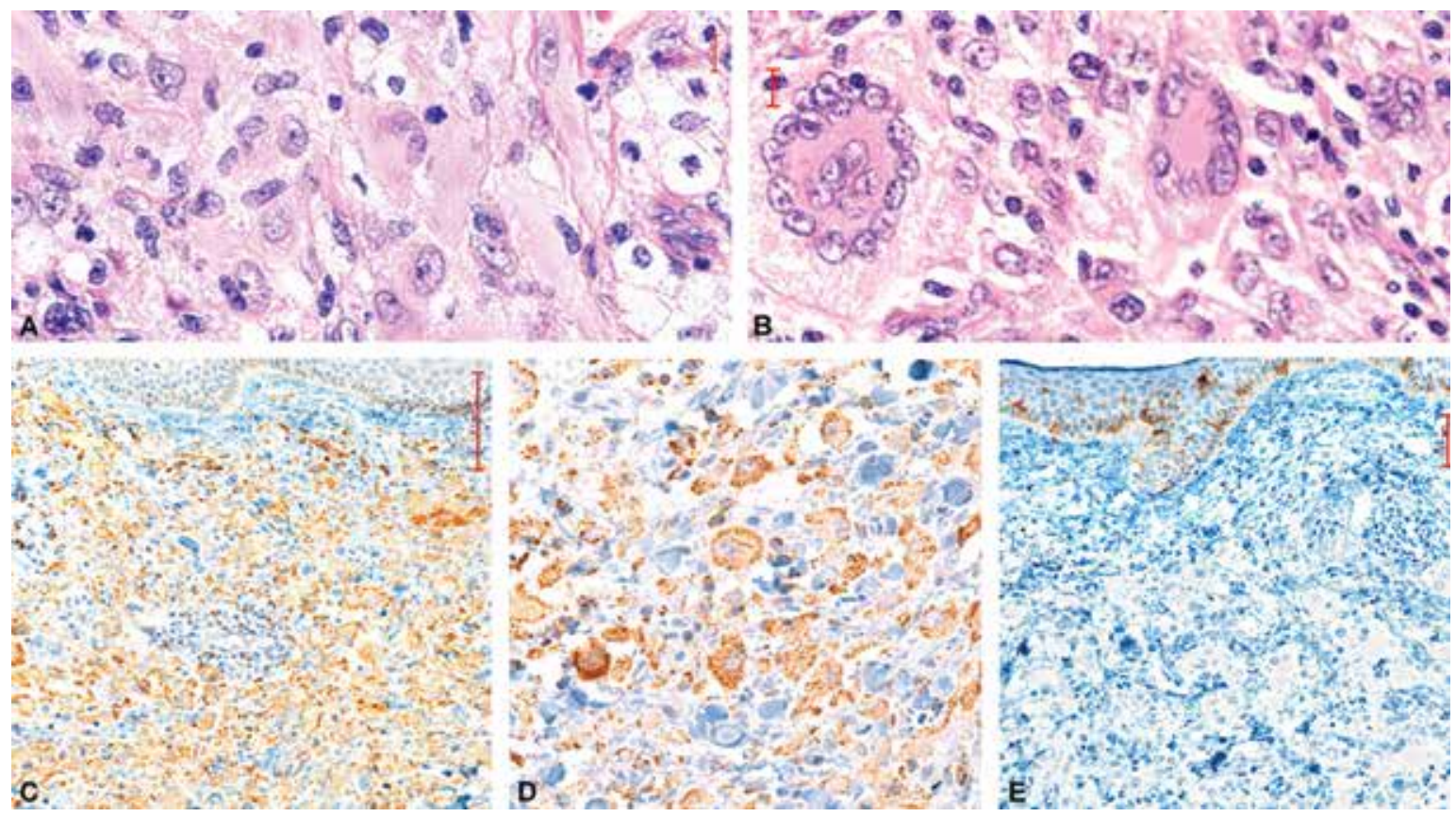

FIGURA 6. Xantogranuloma. A. Histiocitos con núcleos ovales y citoplasmas eosinófilos. Hay algunas células xantomizadas en el lado derecho. Hematoxilina y eosina, 20X. B. Células de Touton con núcleos en guirnalda completa y citoplasma periférico xantomizado. Hematoxilina y eosina, 2oX. C. Inmunohistoquímica: CD68 positivo en el citoplasma de los histiocitos, 10X. D. Inmunohistoquímica: CD68 positivo en el citoplasma de los histiocitos, 20X. E. Inmunohistoquímica: CD1a negativo, 10X.

\begin{tabular}{llll}
\hline COMPROMISO & XANTOGRANULOMA JUVENIL & NO XANTOGRANULOMA JUVENIL \\
\hline - Cutáneo & - Xantogranuloma juvenil & Reticulohistiocitoma primario \\
& - Histiocitoma eruptivo generalizado & \\
& - Histiocitosis cefálica benigna & \\
Cutáneo y sistémico & Xantoma diseminado & Reticulohistiocitosis multicéntrica \\
Sistémico & Enfermedad de Erdheim-Chester & Enfermedad de Rosai-Dorfman \\
\hline
\end{tabular}

TABLA 4. Clasificación práctica de las histiocitosis no Langerhans con base en el tipo de compromiso cutáneo o sistémico y las características inmunofenotípicas. 
los histiocitos en el estado más inmaduro aparecen a una edad temprana, con un curso clínico corto y de resolución espontánea, como es el caso de la histiocitosis cefálica benigna y el xantogranuloma juvenil. A medida que se afectan histiocitos en un estado más maduro, la edad de presentación también aumenta y el curso clínico de la enfermedad es más progresivo y resistente al tratamiento, como en la reticulohistiocitosis y la histiocitosis nodular progresiva ${ }^{42,44}$.

\section{Patogénesis}

Al igual que las de células de Langerhans, las histiocitosis de células no Langerhans tienen una patogénesis desconocida. La mayoría se derivan de una célula dendrítica intersticial, otras, de monocitos ma-

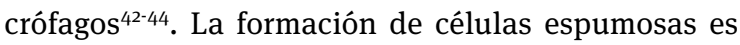
la característica prominente; se cree que los lípidos se acumulan en los histiocitos como resultado de un aumento en la captación y la biosíntesis intracelular, más que un aumento en los niveles séricos, pues en los pacientes afectados los lípidos séricos son normales $^{43}$. Se ha sugerido que factores ambientales, como los virus, o factores físicos, como el trauma, pueden actuar como desencadenantes ${ }^{45}$.

En un intento por unificar un concepto de las histiocitosis de células no Langerhans, se han descrito diferentes tipos morfológicos mayores de histiocitos que hacen parte de un espectro continuo de maduración celular: mononucleares que pueden ser festoneados, vacuolizados, xantomizados, fusiformes $\mathrm{u}$ oncocíticos (FIGURA 6, A); y multinucleares, como las células de Touton (FIGURA 6, B), células en vidrio esmerilado, células de Langhans o células de cuerpo extraño ${ }^{42,46}$. Dependiendo del subtipo de histiocitosis de células no Langerhans, predomina un tipo de histiocito o todos ellos ${ }^{44}$.

\section{Manifestaciones clínicas}

Antes de abordar la presentación clínica, es importante aclarar que a lo largo de la historia ha sido difícil unificar la clasificación de este grupo de enfermedades, debido a la gran variedad de entidades comprendidas en este espectro ${ }^{6}$. Un abordaje práctico se basa en las características clínicas e inmunofenotípicas, dividiendo las histiocitosis de células no Langerhans en tres grupos: las que afectan predominantemente la piel, las que afectan la piel, pero también tienen un compromiso sistémico, y las que son predominantemente sistémicas, pero pueden afectar la piel (TABLA 4) ${ }^{42}$.
XANTOGRANULOMA JUVENIL: Es la más común de todas las histiocitosis y corresponde al $90 \%$ de los $\operatorname{casos}^{47}$. El $80 \%$ de los casos ocurre en el primer año de vida, de los cuales el $20 \%$ están presentes desde el nacimiento $^{3}$. Aunque es raro, también se han reportado casos en adultos entre los 20 y los 30 años de edad ${ }^{48}$. Existe una predominancia en hombres, cuando se trata de lesiones múltiples ${ }^{43,47}$.

Se presenta con lesiones inicialmente de color rojo naranja o rojo café, que rápidamente se tornan amarillas; usualmente son asintomáticas, pero pueden ulcerarse y acompañarse de prurito o dolor ${ }^{47,49}$. La localización más común es en cabeza y cuello, seguida del tronco superior, las extremidades superiores y las inferiores ${ }^{3,43}$ (FIGURA 7).

Existen dos formas de presentación: la papular, o micronodular, con lesiones múltiples en forma de domo de 2 a $5 \mathrm{~mm}$ y dispersas en la parte superior del cuerpo; y la nodular, o macronodular, con una o dos lesiones de 1 a 2 $\mathrm{cm}$, traslúcidas y con telangiectasias en la superficie; se utiliza el término gigante, cuando exceden los $2 \mathrm{~cm}^{50,51}$.

En la mayoría de los pacientes la enfermedad se limita a la piel, con un curso clínico benigno y regresión espontánea en 3 a 6 años ${ }^{47,49}$. Sin embargo, también se reporta compromiso extracutáneo, siendo el ojo el más afectado, presente en el o,5 \% de los pacientes con lesiones cutáneas; generalmente, ocurre antes de los dos años de edad, con complicaciones graves como hifema y glaucoma que pueden llevar a ceguera. Es recomendable, entonces, remitir al paciente tempranamente al oftalmólogo ${ }^{52}$. El pulmón es el segundo sitio de afectación extracutánea, seguido del hueso y el sistema nervioso central, entre otros ${ }^{53}$.

Otras asociaciones descritas incluyen la presencia de máculas de color café con leche en el contexto de la neurofibromatosis de tipo $1^{54} \mathrm{y}$ de la leucemia mielomonocítica juvenil ${ }^{55}$.

XANTOMA PAPULAR: Es una entidad xantomatosa normolipémica rara que ocurre principalmente en adultos ${ }^{56}$. Es considerada por algunos como una variante del xantogranuloma juvenil ${ }^{43}$. Clínicamente, se presenta con pápulas y nódulos redondos, asintomáticos, de color amarillo naranja, que tienen predilección por cabeza, cuello, tronco, extremidades superiores y, raramente, mucosas ${ }^{57}$. Su curso clínico es de resolución espontánea ${ }^{43}$.

HISTIOCITOMA ERUPTIVO GENERALIZADO: Es una forma muy rara de presentación ${ }^{58}$. El $25 \%$ de los casos se inician en la infancia y, el $75 \%$, entre la tercera y la sexta década de la vida; tiene predilección por el sexo masculino ${ }^{3}$. Se manifiesta con brotes recurrentes de 


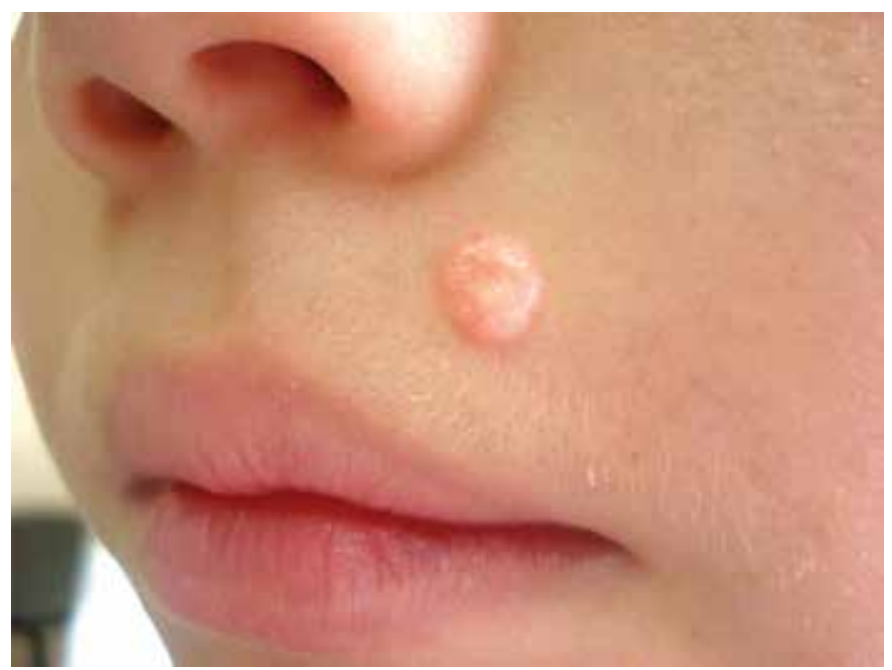

FIGURA 7. Xantogranuloma juvenil: nódulo xantomatoso supralabial. pápulas asintomáticas de color rojo café, localizadas en el tronco, las extremidades proximales y, ocasionalmente, la cara. En los adultos, puede haber compromiso de las mucosas ${ }^{59,60}$. Las lesiones remiten en meses a años, dejando hiperpigmentación residual ${ }^{3}$.

HISTIOCITOSIS CEFÁLICA BENIGNA: También es una entidad poco frecuente. Usualmente, se inicia al año de vida y casi todos los casos se presentan en los primeros tres años ${ }^{61,62}$. Algunos lo consideran una variante localizada del histiocitoma eruptivo generalizado $^{43}$. Clínicamente, se pueden encontrar máculas y pápulas, de color rojo café, de 2 a $5 \mathrm{~mm}$, asintomáticas, inicialmente en las mejillas, los párpados y la frente, con subsecuente aparición en las orejas y el cuello. Ocasionalmente, las lesiones pueden desarrollarse en el tronco y los brazos, y más raramente, en las piernas y los glúteos ${ }^{61-63}$ (FIGURA 8). En general, se trata de pacientes por lo demás sanos; sin embargo, hay dos casos reportados en la literatura asociados a diabetes insípida $^{64,65}$. La mayoría de los casos presentan resolución espontánea en 8 meses a 4 años ${ }^{61-63}$.

HISTIOCITOSIS NODULAR PROGRESIVA: Es una entidad muy rara que puede ocurrir a cualquier edad, pero afecta principalmente a pacientes entre la quinta y sexta década de la vida. Se caracteriza por comprometer tanto la piel como las mucosas ${ }^{66}$. En la piel se presenta como una erupción de cientos de lesiones de dos tipos diferentes. En el primero, se trata de pápulas superficiales amarillas o anaranjadas, de 2 a 10

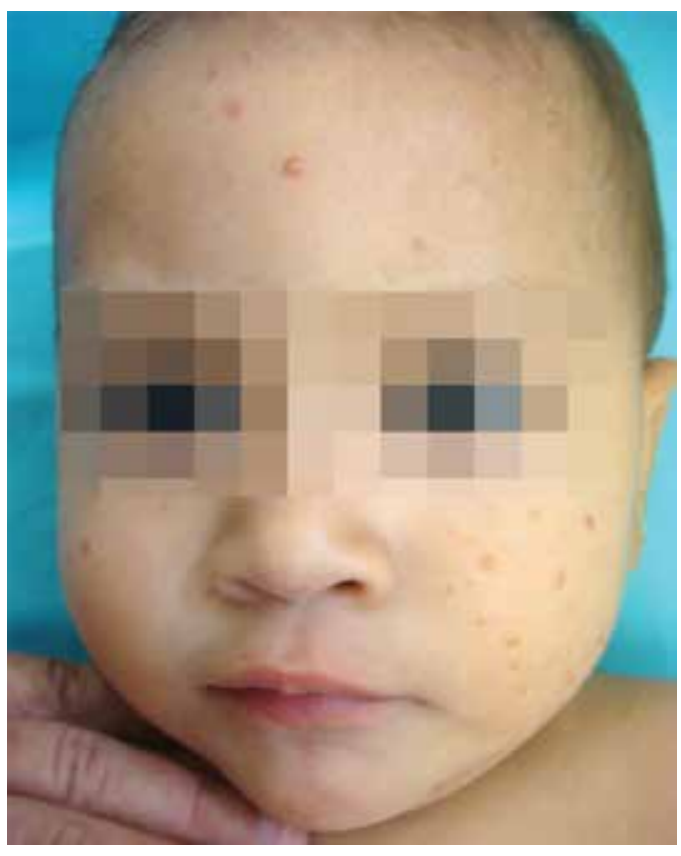

FIGURA 8. Histiocitosis cefálica benigna: múltiples pápulas de color marrón en la cara.

$\mathrm{mm}$, dispersas en todo el cuerpo, pero respetando los pliegues y las zonas periarticulares. El segundo tipo se manifiesta como nódulos profundos con telangiectasias, de 1 a $5 \mathrm{~cm}$, principalmente en el tronco; esta es la forma de presentación más común, por la cual recibe su nombre ${ }^{66-68}$. Cuando las lesiones se tornan 
coalescentes, pueden producir facies leonina. Entre las mucosas comprometidas están la oral, la laríngea y la conjuntival. Se han descrito asociaciones con tumores hipotalámicos, hepatoesplenomegalia, hipotirodismo, hiperuricemia y leucemia mieolide crónica ${ }^{69}$. Su curso clínico es progresivo, sin involución espontánea ${ }^{66-69}$.

XANTOMA DISEMINADO: Es una entidad rara, que tiene predominio en el sexo masculino. La edad de presentación es variable, el $60 \%$ desarrolla la enfermedad antes de los 25 años de edad ${ }^{70,71}$. Se caracteriza por la tríada de xantomas cutáneos, xantomas de mucosas y diabetes insípida ${ }^{3}$. La lesión primaria en la piel son pápulas amarillas o color rojo café, múltiples, distribuidas simétricamente en la cara, los pliegues y las extremidades proximales, que llegan a agruparse en placas grandes, en ocasiones atróficas ${ }^{70,71}$. El compromiso de mucosas está presente en 40 a $60 \%$ de los pacientes, siendo las vías respiratorias superiores y la mucosa oral los sitios más implicados; también, puede haber lesiones conjuntivales y corneales ${ }^{47}$. La diabetes insípida se presenta en $40 \%$ de los casos, usualmente es leve y sensible a la vasopresina ${ }^{72}$. Otras asociaciones raras incluyen gammapatías monoclonales, discrasias de células plasmáticas y alteraciones tiroideas ${ }^{3}$. Se ha sugerido que el curso clínico es variable: raramente se presenta resolución espontánea; lo más común es que las lesiones sean persistentes; es muy rara la forma progresiva, con disfunción orgánica y compromiso del sistema nervioso central ${ }^{71}$.

XANTOGRANULOMA NECROBIÓTICO: Es una entidad rara con compromiso multisistémico. Algunos autores lo consideran una entidad aparte, por lo que no se incluye en la clasificación de Weitzman ${ }^{42}$; no obstante, otros lo incluyen dentro del grupo de histiocitosis de células no Langerhans ${ }^{3}$. Ocurre por igual en ambos sexos y la principal edad de presentación es la sexta década de la vida ${ }^{3,73}$. El $90 \%$ de los pacientes tiene paraproteinemia asociada, principalmente de tipo IgG, y, aproximadamente, el $10 \%$ progresa a mieloma múltiple $\mathrm{e}^{47,74,75}$. Clínicamente, se caracteriza por nódulos y placas infiltradas amarillas o rojas, algunas con atrofia, ulceración y telangiectasias. Se localizan predominantemente en la región periorbitaria, donde pueden asociarse con compromiso ocular, y es menos común en el tronco y las extremidades. Otros hallazgos incluyen anemia, leucopenia, elevación de la eritrosedimentación y hepatoesplenomegalia ${ }^{73,75}$. Su curso clínico es crónico y progresivo, y el pronóstico depende de la malignidad asociada ${ }^{47}$.

\section{ENFERMEDAD DE ERDHEIM-CHESTER}

Se considera una variable del xantoma diseminado ${ }^{43}$, acompañada de manifestaciones óseas como la osteoesclerosis de los huesos largos ${ }^{76}$. Afecta principalmente a adultos en edad media y mayores ${ }^{69}$. El compromiso de la piel ocurre en menos de $25 \%$ de los pacientes, como pápulas y nódulos amarillos o de color rojo café, localizados en párpados, cuero cabelludo, cuello, tronco y axilas $^{77}$. El signo más común es el dolor crónico óseo, generalmente en las extremidades inferiores; en las formas más graves se presenta infiltración del sistema nervioso central y se desarrolla diabetes insípida ${ }^{74}$. El pronóstico es pobre, con un curso clínico progresivo con fibrosis pulmonar concomitante ${ }^{69}$.

\section{RETICULOHISTIOCITOSIS}

Incluye dos tipos de entidades: el reticulohistiocitoma solitario, más frecuente en adultos jóvenes, y la reticulohistiocitosis multicéntrica, que predomina en mujeres en la cuarta década de la vida ${ }^{3,78}$. El reticulohistiocitoma solitario se caracteriza por un nódulo amarillo a rojo, asintomático, principalmente en la cabeza, el tronco o las extremidades ${ }^{78}$. En la forma multicéntrica se presentan múltiples reticulohistiocitomas. En piel estas lesiones favorecen la distribución acral especialmente las manos en la parte dorsolateral de los dedos y las áreas periungulares donde adquieren una apariencia en "cuentas de coral" y los codos, siendo muy similares a los nódulos reumatoides y también asociados con artropatía grave $\mathrm{j}^{78-80}$. Otras manifestaciones incluyen reticulohistiocitomas en mucosas, hiperlipidemia (30-60 \%), neoplasias (25\%) o enfermedades autoinmunitarias $(17 \%)^{47}$. La forma solitaria presenta resolución espontánea. Cuando se trata de lesiones múltiples, la enfermedad es progresiva, con casos de artritis que produce mutilación o de desfiguración ${ }^{47}$.

\section{ENFERMEDAD DE ROSAI-DORFMAN}

Se conoce también como histiocitosis sinusal con linfadenopatías masivas ${ }^{3,4778}$. Es una entidad rara, de distribución mundial, pero la mayoría de los casos se reportan en el oeste de la India y el Âfrica; afecta principalmente a niños y adultos jóvenes ${ }^{3}$. Su característica principal son las linfadenopatías bilaterales cervicales masivas, pero estas pueden desarrollarse en cualquier sitio. El compromiso de la piel ocurre en el $10 \%$ de los pacientes, en algunos casos como signo inicial de la enfermedad; se presentan lesiones múltiples polimorfas, máculas, pápulas, nódulos y placas de color rojo café o xantomatosas, que pueden erosionarse o ulcerarse; la región malar y los párpados son los sitios de mayor compromiso ${ }^{78,81}$. En la mayoría de los pacientes, 
el curso clínico es benigno con resolución espontánea, primero, de las lesiones extraganglionares, mientras que las adenopatías pueden persistir por años ${ }^{47}$.

\section{Diagnóstico}

Debido al amplio número de enfermedades agrupadas como histiocitosis de células no Langerhans y a la similitud de las características clínicas, la biopsia de piel es una herramienta imprescindible para el diagnóstico.

Las lesiones de la familia del xantogranuloma juvenil muestran características similares, encontrándose en la dermis un infiltrado celular denso compuesto por histiocitos mononucleares y multinucleares; específicamente, las células de Touton pueden estar presentes en el $85 \%$ de los casos, pero no son necesarias para el diagnóstico (FIGURA 6, B). Característicamente, se presentan como una corona de núcleos que encierran un centro de material eosinofílico y, en la periferia, un anillo de citoplasma espumoso xantomizado. Otras células inflamatorias que pueden verse en diferentes grados, incluyen linfocitos, eosinófilos, neutrófilos y células plasmáticas (FIGURA 6, A) ${ }^{3,8}$.
En las entidades pertenecientes a la familia xantogranuloma no juvenil, los hallazgos son más específicos. En la enfermedad de Rosai-Dorfman, el infiltrado está compuesto por histiocitos con abundante citoplasma eosinofílico mezclado con linfocitos y, ocasionalmente, células plasmáticas (FIGURA 9, A); también, puede observarse el fenómeno de emperipolesis (FIGURA 9, B). El CD68 (FIGURA 9, C) y la proteína S10o (FIGURA 9, D) son algunos de los marcadores de inmunohistoquímica expresados ${ }^{78,81}$. La reticulohistiocitosis se caracteriza por un denso infiltrado dérmico de linfocitos e histiocitos, mononucleares o multinucleares, con un citoplasma granular eosinofílico con apariencia de vidrio esmerilado ${ }^{78-80}$. En la enfermedad de Erdheim-Chester, la mayoría del infiltrado está compuesto por histiocitos espumosos y células de Touton, con fibrosis variable y presencia de linfocitos y células plasmáticas $^{76,77}$.

\section{Diagnóstico diferencial}

Al igual que las histiocitosis de células de Langerhans, las de células no Langerhans comprenden un grupo
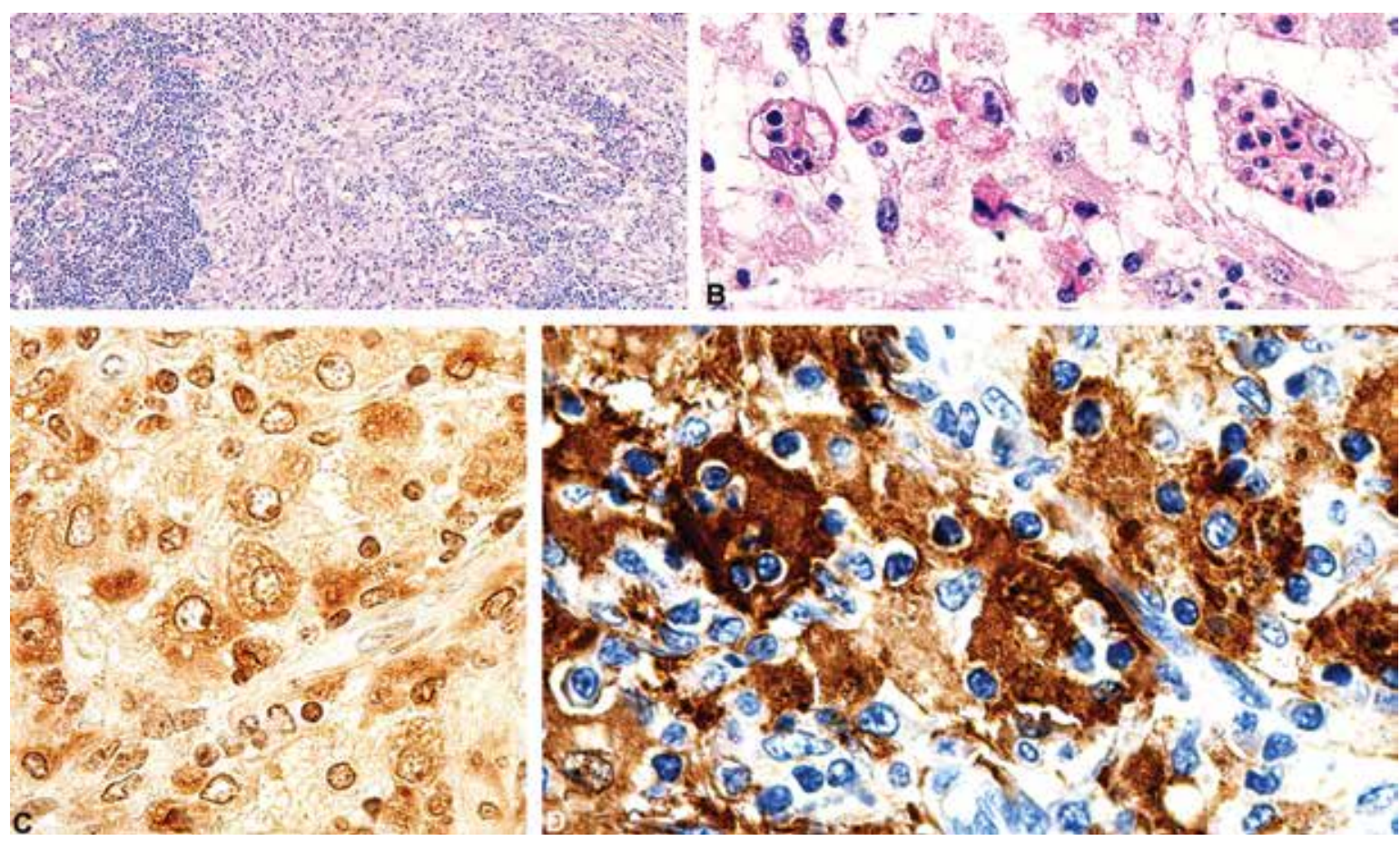

FIGURA 9. Enfermedad de Rosai-Dorfman. A. Infiltrado difuso de linfocitos, histiocitos y plasmocitos. Hematoxilina y eosina, 1oX. B. Fagocitosis de restos nucleares por parte de los histiocitos (emperipolesis). Hematoxilina y eosina, 40X. C. Inmunohistoquímica: positiva para CD68, 40X. D. Inmunohistoquímica: positiva para S100, 40X. 
amplio de diagnósticos diferenciales. Estos pueden agruparse según la morfología de las lesiones: si son pápulas o nódulos, deben diferenciarse de molusco contagioso, nevos de Spitz, mastocitoma solitario, siringomas eruptivos, xantomas eruptivos y tumores de anexos; cuando se trata de placas, los principales diagnósticos diferenciales incluyen granuloma anular, sarcoidosis, lepra lepromatosa, necrobiosis lipoídica y xantomas planos 3,43 .

\section{Tratamiento}

La mayoría de las formas de histiocitosis de células no Langerhans no requieren tratamiento, porque su curso clínico es asintomático y de resolución espontánea, como es el caso del xantogranuloma juvenil, el xantoma papular, la histiocitosis eruptiva generalizada y la histiocitosis cefálica benigna. El tratamiento es necesario para las enfermedades con curso clínico progresivo o compromiso sistémico importante, como la histiocitosis nodular progresiva, el xantoma diseminado, la reticulohistiocitosis, la enfermedad de Erdeim-Chester y la enfermedad de Rosai-Dorfman ${ }^{3,43}$. Sin embargo, los tratamientos disponibles son escasos, muchos basados en reportes de casos. Las recomendaciones especiales incluyen las siguientes.

- Xantogranuloma juvenil. Puede practicarse escisión quirúrgica para fines $\operatorname{cosméticos}^{3,49}$. Para los casos con compromiso sistémico, se ha recomendado la radioterapia, los corticoesteroides sistémicos, la ciclosporina o el metotrexato ${ }^{49}$.

- Histiocitosis eruptiva generalizada. Por la extensión de las lesiones, existen reportes de tratamientos sistémicos con isotretinoína ${ }^{82}$ y la fototerapia $\mathrm{PUVA}^{83}$.

- Histiocitosis cefálica benigna. Debe hacerse seguimiento para vigilar las exacerbaciones o el desarrollo de diabetes insípida, aunque esto es raro ${ }^{64,65}$.

- Histiocitosis nodular progresiva. El tratamiento incluye corticoesteroides intralesionales o sistémicos, ciclofosfamida, vincristina o prednisolona, pero, ninguno de estos ha logrado modificar el curso progresivo de la enfermedad. A las lesiones más grandes puede practicárseles escisión quirúrgica o tratamiento con láser ablativo de $\mathrm{CO}_{2}{ }^{47,67}$.
- Xantoma diseminado. Para el compromiso local, se reporta el uso de láser de $\mathrm{CO}_{2}$, electrocoagulación y corticoesteroides intralesionales, con reacción variable. Para el compromiso sistémico, se han usado vinblastina, radioterapia, corticoesteroides sistémicos, azatioprina y radioterapia, y vasopresina, para la diabetes ${ }^{47,70,72}$.

- Xantogranuloma necrobiótico. Se han utilizado varios tratamientos con resultados limitados. Las lesiones en piel han sido tratadas con clorambucilo, melfalan o ciclofosfamida (con corticoesteroides sistémicos asociados o sin ellos); también, se han utilizado terapias destructivas como radioterapia o láser de $\mathrm{CO}_{2}^{47,73,75}$. La reacción terapéutica a los corticoesteroides tópicos o intralesiones es mínima ${ }^{3}$.

- Enfermedad de Erdheim-Chester. Hasta el momento, no se ha establecido un tratamiento totalmente óptimo. Los corticoesteroides sistémicos, los agentes citotóxicos, los productos biológicos, la radioterapia y el trasplante de médula ósea, se han utilizado con resultados variables. Actualmente, la primera línea es el interferón alfa ${ }^{76,77}$.

- Reticulohistiocitosis. La escisión quirúrgica es de elección para el reticulohistiocitoma solitario $^{3,43}$. Para las lesiones múltiples, la mayoría de los tratamientos sistémicos no han sido efectivos. Se han descrito tratamientos con antiinflamatorios no esteroideos y corticoesteroides intralesionales o sistémicos, para el compromiso articular. Otros agentes, como metotrexato, leflunomida, hidroxicloroquina y azatioprina, tienen una evidencia clínica más limitada; en algunos casos, pueden combinarse con productos biológicos como el antifactor de necrosis tumoral alfa. En los casos asociados con malignidad, pueden utilizarse clorambucilo y ciclofosfamida ${ }^{47,78,80}$.

- Enfermedad de Rosai-Dorfman. Muchas lesiones son asintomáticas y curan espontáneamente sin requerir tratamiento. Cuando se requiere por ser lesiones destructivas o persistentes, se han descrito casos tratados con radioterapia, escisión quirúrgica, corticoesteroides sistémicos y agentes quimioterapéuticos, como vinblastina y etopósido ${ }^{3,78}$. 


\section{HISTIOCITOSIS}

\section{INDETERMINADAS}

Aunque no están incluidas como un tipo específico de histiocitosis en la clasificación de 1987, es importante mencionar este grupo de enfermedades, muy raras y algo controversiales, las cuales presentan características inmunofenotípicas de histiocitosis de células de Langerhans y de histiocitosis de células no Langerhans. Inicialmente, se pensó que estaban estrechamente relacionadas con las histiocitosis de células de Langerhans debido a que las células de las lesiones eran positivas para S100 y CD1a, pero carecían de gránulos de Birbeck. Sin embargo, después se demostró que estas células también expresaban marcadores de monocitos o macrófagos, lo que llevó a considerarlas como un trastorno de superposición entre histiocitosis de células de Langerhans e histiocitosis de células no Langerhans ${ }^{84,85}$.

\section{Epidemiología}

Son extremadamente raras, sin predisposición según el sexo. La mayoría de los casos ocurre en adultos, pero también, se han reportado en niños o casos congénitos ${ }^{3,86}$.

\section{Patogénesis}

Su patogénesis se desconoce; actualmente, se cuestiona si es una entidad separada o si representa una variante de la histiocitosis de células no Langerhans ${ }^{3}$. Se ha propuesto que se trata de células precursoras de Langerhans que están inmaduras y aún no han adquirido los gránulos de Birbeck, o que se derivan de células de Langerhans que han perdido los gránulos de Birbeck a medida que migran hacia los ganglios linfáticos, o que pertenecen a un grupo independiente de células dendríticas epidérmicas ${ }^{8}$.

\section{Manifestaciones clínicas}

Existen dos formas de presentación: solitaria y generalizada. La forma solitaria se presenta como un nódulo eritematoso blando que puede ulcerarse y que, con el tiempo, se torna de color café o amarillo. Las lesiones múltiples se ven como pápulas y nódulos hasta de un $\mathrm{cm}$, de color rojo café, que tienden a aparecer en brotes sucesivos ${ }^{3,8,87}$. La enfermedad se localiza en el tronco $\mathrm{y}$ en las extremidades principalmente, pero también, se ha reportado compromiso de cabeza, cuello y ge- nitales ${ }^{88}$. Generalmente, es una entidad limitada a la piel, pero se ha descrito compromiso de la mucosa ocular $^{89}$, al igual que el de vísceras o hueso, o incluso, la muerte ${ }^{3}$. Una rara asociación es la de algunos casos con leucemia ${ }^{90,91}$.

\section{Diagnóstico}

Se caracteriza por un infiltrado dérmico monomorfo de histiocitos, que puede extenderse al tejido celular subcutáneo. El epidermotropismo está ausente. Los histiocitos tienen forma onicocítica principalmente, pero también, pueden verse fusiformes, festoneados o vacuolados, y células de Touton. Los linfocitos son frecuentes y raramente se observan eosinófilos. El inmunofenotipo muestra expresión de S100, CD1a, HAM56, CD68, factor XIIIa, lisozima y HLA-DR. La langerina (CD207) no está expresada. Por definición, en la microscopía electrónica hay ausencia de gránulos de Birbeck ${ }^{3,8,87}$.

\section{Diagnóstico diferencial}

Pueden encontrarse lesiones similares en la histiocitosis cefálica benigna, el histiocitoma eruptivo generalizado, el xantogranuloma juvenil y la reticulohistiocitosis congénita de resolución espontánea3,92.

\section{Tratamiento}

Generalmente no se requiere debido a que la condición es de resolución espontánea y no progresiva, en la mayoría de los casos. Las lesiones únicas pueden removerse por cirugía ${ }^{85}$. Para las lesiones múltiples no hay un tratamiento estandarizado; las terapias descritas incluyen: fototerapia PUVA $^{93}$ o $\mathrm{UVB}^{94}$, talidomida ${ }^{87}$, metotrexato ${ }^{95}$, pravastatina ${ }^{96}$, radioterapia corporal total con haz de electrones ${ }^{97}$ o quimioterapia sistémica para casos con compromiso extenso ${ }^{84}$.

\section{CONCLUSIÓN}

Las histiocitosis continúan siendo un grupo complejo de enfermedades, aún con muchas preguntas por responder, pueden superponerse o, incluso, progresar unas a otras. Se requieren más datos epidemiológicos, pues muchos casos no son diagnosticados o, si se diagnostican, se limitan a reportes de caso. Su clasificación es confusa; el dermatólogo debe estar en capacidad de reconocer aquellas que comprometen la piel de manera más frecuente. En general, la supervivencia es buena, 
con un curso clínico benigno y resolución espontánea, Sin embargo, cuando los histiocitos infiltran órganos vitales, pasan de ser entidades benignas a agresivas; por eso, es importante estar alerta ante los signos de compromiso extracutáneo.

\section{Agradecimientos}

Por la figura 4, a la María Elizabeth Gaviria, por las figuras 5 y 8, a María Cristina Trujillo, y por la figura 7, a Liliana Tamayo.

\section{REFERENCIAS}

1. Gelmetti C. Cutaneous Langerhans Cell Histiocytosis. En: Goldsmith LA, Katz SI, Gilchrest BA, Paller AS, Leffel DJ, Wolff K. Fitzpatrick's dermatology in general medicine. 8va ed. New York: McGraw-Hill Medical; 2012.p.1414-24

2. Shahlaee AH, Arceci RJ. Histiocytic disorders. En: Arceci R, Hann IM, Smith OP. Pediatric hematology. 3ed. Malden, Mass.: Blackwell Pub.; 2006.p.340-359

3. Goodman WT, Barret TL. Histiocytoses. En:Bolognia J, Lorizzo JL, Schaffer JV. Dermatology: [ExpertConsult]. 3rd ed. Edinburgh: Elsevier, Saunders; 2012.p.1529-1546.

4. Windebank K, Visser J, Nanduri V. Advances in the management of histiocytic disorders 2011. Paediatrics and Child Health. 2012;22:108-14.

5. Histiocytosis syndromes in children. Writing Group of the Histiocyte Society. Lancet Lond Engl. 1987;1:208-9.

6. Favara BE, Feller AC, Pauli M, Jaffe ES, Weiss LM, Arico M, et al. Contemporary classification of histiocytic disorders. The WHO Committee On Histiocytic/Reticulum Cell Proliferations. Reclassification Working Group of the Histiocyte Society. Med Pediatr Oncol. 1997;29:157-66.

7. El Demellawy D, Young JL, de Nanassy J, Chernetsova E, Nasr A. Langerhans cell histiocytosis: a comprehensive review. Pathology. 2015;47:294-301.

8. Goodlad J, Calonje E. Cutaneous lymphoproliferative diseases and related disorders. En: Calonje E, Brenn T, Lazzar A. MacKee PH, editores. McKee's pathology of the skin: with clinical correlations. 4th ed. Edinburgh: Elsevier, Saunders; 2012.p.1311-1420

9. Nicholson HS, Egeler RM, Nesbit ME. The epidemiology of Langerhans cell histiocytosis. Hematol Oncol Clin North Am. 1998;12:379-84.

10. Kwon SH, Choi JW, Kim HJ, Youn SW. Langerhans cell histiocytosis: a retrospective analysis in a Korean tertiary hospital from 2003 to 2012. J Dermatol. 2013;40:824-8.

11. Guyot-Goubin A, Donadieu J, Barkaoui M, Bellec S, Thomas C, Clavel J. Descriptive epidemiology of childhood Langerhans cell histiocytosis in France, 2000-2004. Pediatr Blood Cancer. 2008;51:71-5.

12. Aricò M, Nichols K, Whitlock JA, Arceci R, Haupt R, Mittler U, et al. Familial clustering of Langerhans cell histiocytosis. $\mathrm{Br} \mathrm{J}$ Haematol. 1999;107:883-8.
13. Edelbroek JR, Vermeer MH, Jansen PM, Stoof TJ, van der Linden MMD, Horváth B, et al. Langerhans cell histiocytosis first presenting in the skin in adults: frequent association with a second haematological malignancy. Br J Dermatol. 2012;167:1287-94.

14. Egeler RM, Neglia JP, Aricò M, Favara BE, Heitger A, Nesbit $\mathrm{ME}$, et al. The relation of Langerhans cell histiocytosis to acute leukemia, lymphomas, and other solid tumors. The LCH-Malignancy Study Group of the Histiocyte Society. Hematol Oncol Clin North Am. 1998;12:369-78.

15. Ariza SA, Cardona AF, Rueda X. Histiocitiosis de células de Langerhans. Diez años de experiencia en el Instituto Nacional de Cancerología. Rev Asoc Colomb Dermatol. 2008;16:178-84.

16. Abla O, Egeler RM, Weitzman S. Langerhans cell histiocytosis: Current concepts and treatments. Cancer Treat Rev. 2010;36:354-9.

17. McClain K, Jin H, Gresik V, Favara B. Langerhans cell histiocytosis: lack of a viral etiology. Am J Hematol. 1994;47:16-20.

18. Toro AM, Rodrigo R, Ochoa A. Histiocitosis de células de Langerhans. Rev Asoc Colomb Dermatol. 2009;17:34-44.

19. Vaiselbuh SR, Bryceson YT, Allen CE, Whitlock JA, Abla O. Updates on histiocytic disorders. Pediatr Blood Cancer. 2014;61:1329-35.

20. Badalian-Very G, Vergilio J-A, Degar BA, MacConaill LE, Brandner B, Calicchio ML, et al. Recurrent BRAF mutations in Langerhans cell histiocytosis. Blood. 2010;116:1919-23.

21. Oishi N, Kondo T, Mochizuki K, Inoue T, Kasai K, Nakazawa T, et al. Localized Langerhans cell histiocytosis of the thymus with BRAF V6ooE mutation: a case report with immunohistochemical and genetic analyses. Hum Pathol. 2014;45:1302-5.

22. Paller A, Mancini AJ. Histiocytoses and Malignant Skin Diseases. En: Paller A, Mancini AJ. Hurwitz clinical pediatric dermatology. 4th ed. Edinburgh ; New York: Elsevier Saunders; 2011.p.219.233.

23. Munn S, Chu AC. Langerhans cell histiocytosis of the skin. Hematol Oncol Clin North Am. 1998;12:269-86.

24. Valdivielso M, Bueno C. [Langerhans cell histiocytosis]. Actas Dermo-Sifiliográficas. 2005;96:275-84.

25. Aruna DR, Pushpalatha G, Galgali S, Prashanthy null. Langerhans cell histiocytosis. J Indian Soc Periodontol. 2011;15:276-9.

26. Querings K, Starz H, Balda B-R. Clinical spectrum of cutaneous Langerhans' cell histiocytosis mimicking various diseases. Acta Derm Venereol. 2006;86:39-43.

27. Mataix J, Betlloch I, Lucas-Costa A, Pérez-Crespo M, Moscardó-Guilleme C. Nail changes in Langerhans cell histiocytosis: a possible marker of multisystem disease. Pediatr Dermatol. 2008;25:247-51.

28. Haupt R, Minkov M, Astigarraga I, Schäfer E, Nanduri V, Jubran R, et al. Langerhans cell histiocytosis (LCH): guidelines for diagnosis, clinical work-up, and treatment for patients till the age of 18 years. Pediatr Blood Cancer. 2013;60:175-84.

29. Broadbent V, Gadner H, Komp DM, Ladisch S. Histiocytosis syndromes in children: II. Approach to the clinical and laboratory evaluation of children with Langerhans cell histiocytosis. Clinical Writing Group of the Histiocyte Society. Med Pediatr Oncol. 1989;17:492-5.

30. Valladeau J, Ravel O, Dezutter-Dambuyant C, Moore K, Kleijmeer M, Liu Y, et al. Langerin, a novel C-type lectin specific to Langerhans cells, is an endocytic receptor that induces the formation of Birbeck granules. Immunity. 2000;12:71-81. 
31. Stierman SC, Spicknall KE. Dermatology diagnosis. Langerhans cell histiocytosis. Cutis. 2013;91:64, 67-9.

32. Hoeger PH, Nanduri VR, Harper JI, Atherton DA, Pritchard J. Long term follow up of topical mustine treatment for cutaneous langerhans cell histiocytosis. Arch Dis Child. 2000;82:483-7.

33. Sakai H, Ibe M, Takahashi H, Matsuo S, Okamoto K, Makino I, et al. Satisfactory remission achieved by PUVA therapy in Langerhans cell hisiocytosis in an elderly patient. J Dermatol. 1996;23:42-6.

34. Imafuku S, Shibata S, Tashiro A, Furue M. Cutaneous Langerhans cell histiocytosis in an elderly man successfully treated with narrowband ultraviolet B. Br J Dermatol. 2007;157:1277-9.

35. McClain KL, Kozinetz CA. A phase II trial using thalidomide for Langerhans cell histiocytosis. Pediatr Blood Cancer. 2007;48:44-9.

36. Tsambaos D, Georgiou S, Kapranos N, Monastirli A, Stratigos A, Berger H. Langerhans' cell histiocytosis: complete remission after oral isotretinoin therapy. Acta Derm Venereol. 1995;75:62-4.

37. Steen AE, Steen KH, Bauer R, Bieber T. Successful treatment of cutaneous Langerhans cell histiocytosis with low-dose methotrexate. Br J Dermatol. 2001;145:137-40.

38. Girschikofsky M, Arico M, Castillo D, Chu A, Doberauer C, Fichter J, et al. Management of adult patients with Langerhans cell histiocytosis: recommendations from an expert panel on behalf of Euro-Histio-Net. Orphanet J Rare Dis. 2013;8:72.

39. Charles J, Beani J-C, Fiandrino G, Busser B. Major response to vemurafenib in patient with severe cutaneous Langerhans cell histiocytosis harboring BRAF V6ooE mutation. J Am Acad Dermatol. 2014;71:e97-9.

40. Gadner H, Minkov M, Grois N, Pötschger U, Thiem E, Aricò M, et al. Therapy prolongation improves outcome in multisystem Langerhans cell histiocytosis. Blood. 2013;121:5006-14.

41. Murcia J, Bárcenas W. Histiocitosis. Precop SCP. 2012. 11:36-48.

42. Weitzman S, Jaffe R. Uncommon histiocytic disorders: the non-Langerhans cell histiocytoses. Pediatr Blood Cancer. 2005;45:256-64

43. Gelmetii C. Non-Langerhans Cell Histiocytosis. En: Goldsmith LA, Katz SI, Gilchrest BA, Paller AS, Leffel DJ, Wolff K. Fitzpatrick's Dermatology in General Medicine. 8va ed. New York: McGraw-Hill Medical; 2012.p.1425-50

44. Chu AC. The confusing state of the histiocytoses. Br J Dermatol. 2000;143:475-6.

45. Rodriguez-Jurado R, Duran-McKinster C, Ruiz-Maldonado R. Benign cephalic histiocytosis progressing into juvenile xanthogranuloma: a non-Langerhans cell histiocytosis transforming under the influence of a virus? Am J Dermatopathol. 2000;22:70-4.

46. Zelger BW, Sidoroff A, Orchard G, Cerio R. Non-Langerhans cell histiocytoses. A new unifying concept. Am J Dermatopathol. 1996;18:490-504.

47. Newman B, Hu W, Nigro K, Gilliam AC. Aggressive histiocytic disorders that can involve the skin. J Am Acad Dermatol. 2007;56:302-16.

48. Lovato L, Salerni G, Puig S, Carrera C, Palou J, Malvehy J. Adult xanthogranuloma mimicking basal cell carcinoma: dermoscopy, reflectance confocal microscopy and pathological correlation. Dermatol Basel Switz. 2010;220:66-70.
49. Szczerkowska-Dobosz A, Kozicka D, Purzycka-Bohdan D, Biernat W, Stawczyk M, Nowicki R. Juvenile xanthogranuloma: a rare benign histiocytic disorder. Post $\square$ py Dermatol Alergol. 2014;31:197-200.

50. Gianotti F, Caputo R. Histiocytic syndromes: a review. J Am Acad Dermatol. 1985;13:383-404.

51. Gianotti F. Cutaneous proliferative histiocytosis in children. G Ital Dermatol Venereol. 1980;115:101-5.

52. Samara WA, Khoo CT, Say EA, Saktanasate J, Eagle RC Jr, Shields JA, et al. Juvenile Xanthogranuloma Involving the Eye and Ocular Adnexa: Tumor Control, Visual Outcomes, and Globe Salvage in 30 Patients. Ophthalmology. 2015;122:2130-8

53. Murphy JT, Soeken T, Megison S, Perez E. Juvenile xanthogranuloma: diverse presentations of noncutaneous disease. J Pediatr Hematol Oncol. 2014;36:641-5.

54. Fenot M, Stalder J-F, Barbarot S. Juvenile xanthogranulomas are highly prevalent but transient in young children with neurofibromatosis type 1. J Am Acad Dermatol. 2014;71:389-90.

55. Jans SRR, Schomerus E, Bygum A. Neurofibromatosis type 1 diagnosed in a child based on multiple juvenile xanthogranulomas and juvenile myelomonocytic leukemia. Pediatr Dermatol. 2015;32:e29-32.

56. Alan Arbuckle H, Prok L. Case report--papular xanthoma in a 10-year-old female with abnormal lipid profile. Pediatr Dermatol. 2010;27:86-8.

57. Breier F, Zelger B, Reiter H, Gschnait F, Zelger BWH. Papular xanthoma: a clinicopathological study of 10 cases. J Cutan Pathol. 2002;29:200-6.

58. Cardoso F, Serafini NB, Reis BD, Nuñez MDG, Nery JA da C, Lupi O. Generalized eruptive histiocytoma: a rare disease in an elderly patient. An Bras Dermatol. 2013;88:105-8.

59. Kazi N, Bernert R, Moussa C, Magro C. A case of generalized eruptive histiocytosis in a 23-year-old man. Dermatol Online J. 2014;20(8). pii: 13030/qt39v75449.

6o. Vázquez-Blanco M, Peteiro C, Toribio J. [Generalized eruptive histiocytoma]. Actas Dermo-Sifiliográficas. 2006;97:35-8.

61. Koca R, Bekta S, Altinyazar HC, Sezer T. Benign cephalic histiocytosis: a case report. Ann Dermatol. 2011;23:508-11.

62. Lange M, IDycka-Dwieszewska E, Michajłowski I, Bara $\square$ skaRybak W. Benign cephalic histiocytosis. Cutis. 2015;95:E15-7.

63. Samson JF, Libu GK, Philip M, Simi PS. Benign cephalic histiocytosis. Indian Dermatol Online J. 2013;4:300-1.

64. Weston WL, Travers SH, Mierau GW, Heasley D, Fitzpatrick J. Benign cephalic histiocytosis with diabetes insipidus. Pediatr Dermatol. 2000;17:296-8.

65. Saez-De-Ocariz M, Lopez-Corella E, Duran-McKinster C, Orozco-Covarrubias L, Ruiz-Maldonado R. Benign cephalic histiocytosis preceding the development of insulin-dependent diabetes mellitus. Pediatr Dermatol. 2006;23:101-2.

66. Nofal A, Assaf M, Tawfik A, Elsayed N, Nofal E, Elnakib N, et al. Progressive nodular histiocytosis: a case report and literature review. Int J Dermatol. 2011;50:1546-51.

67. Kunimoto K, Uede K, Furukawa F. Progressive nodular histiocytosis. J Dermatol. 2010;37:1071-3.

68. Hilker O, Kovneristy A, Varga R, Neubert T, Wesselmann U, Flaig MJ, et al. Progressive nodular histiocytosis. J Dtsch Dermatol Ges J Ger Soc Dermatol JDDG. 2013;11:301-7.

69. Caputo R, Marzano AV, Passoni E, Berti E. Unusual variants of non-Langerhans cell histiocytoses. J Am Acad Dermatol. 2007;57:1031-45. 
70. Ansarin H, Berenji Ardestani H, Tabaie SM, Shayanfar N. Xanthoma disseminatum with tumor-like lesion on face. Case Rep Dermatol Med. 2014;2014:621798.

71. Attia AM, Bakry OA, Mohamed EE. Xanthoma disseminatum: a progressive case with multisystem involvement. J Postgrad Med. 2014;60:69-71.

72. Pinto ME, Escalaya GR, Escalaya ME, Pinto JL, Chian CA. Xanthoma disseminatum: case report and literature review. Endocr Pract Off J Am Coll Endocrinol Am Assoc Clin Endocrinol. 2010;16:1003-6.

73. Seastrom S, Bookout A, Hogan DJ. Necrobiotic xanthogranuloma without a monoclonal gammopathy. Cutis. 2014;94:293-6.

74. Pipkin CA, Lio PA. Cutaneous manifestations of internal malignancies: an overview. Dermatol Clin. 2008;26:1-15, vii.

75. Wood AJ, Wagner MVU, Abbott JJ, Gibson LE. Necrobiotic xanthogranuloma: a review of 17 cases with emphasis on clinical and pathologic correlation. Arch Dermatol. 2009;145:279-84.

76. Kim M-S, Kim C-H, Choi S-J, Won C-H, Chang S-E, Lee M-W, et al. Erdheim-chester disease. Ann Dermatol. 2010;22:439-43.

77. Volpicelli ER, Doyle L, Annes JP, Murray MF, Jacobsen E, Murphy GF, et al. Erdheim-Chester disease presenting with cutaneous involvement: a case report and literature review. J Cutan Pathol. 2011;38:280-5.

78. Chisolm SS, Schulman JM, Fox LP. Adult Xanthogranuloma, Reticulohistiocytosis, and Rosai-Dorfman Disease. Dermatol Clin. 2015;33:465-72

79. Islam AD, Naguwa SM, Cheema GS, Hunter JC, Gershwin ME. Multicentric reticulohistiocytosis: a rare yet challenging disease. Clin Rev Allergy Immunol. 2013;45:281-9.

8o. Selmi C, Greenspan A, Huntley A, Gershwin ME. Multicentric reticulohistiocytosis: a critical review. Curr Rheumatol Rep. 2015;17:511.

81. Miceli A, Cleaver N, Spizuoco A. Rosai-Dorfman disease. Cutis. 2015;96:16, 39-40.

82. Kwinter J, DeKoven J. Generalized eruptive histiocytoma treated with isotretinoin. J Cutan Med Surg. 2009;13:146-50.

83. Lan Ma H, Metze D, Luger TA, Steinhoff M. Successful treatment of generalized eruptive histiocytoma with PUVA. J Dtsch Dermatol Ges J Ger Soc Dermatol JDDG. 2007;5:131-4.

84. Wood GS, Hu CH, Beckstead JH, Turner RR, Winkelmann RK. The indeterminate cell proliferative disorder: report of a case manifesting as an unusual cutaneous histiocytosis. J Dermatol Surg Oncol. 1985;11:1111-9.

85. Ratzinger G, Burgdorf WHC, Metze D, Zelger BG, Zelger B. Indeterminate cell histiocytosis: fact or fiction? J Cutan Pathol. 2005;32:552-60.

86. Rodríguez-Jurado R, Vidaurri-de la Cruz H, Durán-Mckinster C, Ruíz-Maldonado R. Indeterminate cell histiocytosis. Clinical and pathologic study in a pediatric patient. Arch Pathol Lab Med. 2003;127:748-51.

87. Tóth B, Katona M, Hársing J, Szepesi A, Kárpáti S. Indeterminate cell histiocytosis in a pediatric patient: successful treatment with thalidomide. Pathol Oncol Res POR. 2012;18:535-8.

88. Martín JM, Jordá E, Martín-Gorgojo A, Beteta G, Monteagudo C. Histiocytosis with mixed cell populations. J Cutan Pathol. 2016;43:456-60.
89. Calatayud M, Güell JL, Gris O, Puig J, Arrondo E, Huguet P. Ocular involvement in a case of systemic indeterminate cell histiocytosis: a case report. Cornea. 2001;20:769-71.

90. Ventura F, Pereira T, da Luz Duarte M, Marques H, Pardal F, Brito C. Indeterminate cell histiocytosis in association with acute myeloid leukemia. Dermatol Res Pract. 2010;2010:569345.

91. Vener C, Soligo D, Berti E, Gianelli U, Servida F, Ceretti E, et al. Indeterminate cell histiocytosis in association with later occurrence of acute myeloblastic leukaemia. Br J Dermatol. 2007;156:1357-61.

92. Haimovic A, Chernoff K, Hale CS, Meehan SA, Schaffer JV. Indeterminate cell histiocytosis that presented clinically as benign cephalic histiocytosis. Dermatol Online J. 2014;20(12). pii: 13030/qt23d5k96k.

93. Wang C-H, Chen G-S. Indeterminate cell histiocytosis: a case report. Kaohsiung J Med Sci. 2004;20:24-30.

94. Logemann N, Thomas B, Yetto T. Indeterminate cell histiocytosis successfully treated with narrowband UVB. Dermatol Online J. 2013;19:20031.

95. Fournier J, Ingraffea A, Pedvis-Leftick A. Successful treatment of indeterminate cell histiocytosis with low-dose methotrexate*. J Dermatol. 2011;38:937-9.

96. Burns MV, Ahmed A, Callahan GB, Le LQ, Cockerell C. Treatment of indeterminate cell histiocytosis with pravastatin. J Am Acad Dermatol. 2011;64:e85-86.

97. Malhomme de la Roche H, Lai-Cheong JE, Calonje E, Davies M, Morris S, Whittaker SJ. Indeterminate cell histiocytosis responding to total skin electron beam therapy. Br J Dermatol. 2008;158:838-40. 